\title{
Mitigating unwanted catches in the southern Iberian hake stock fisheries: Improving fishing technology vs market control policies
}

\author{
José-María Da-Rocha ${ }^{1,2}$, Javier García-Cutrín ${ }^{3}$, María-José Gutiérrez ${ }^{4}$ \\ ${ }^{1}$ ITAM, Centro de Investigación Económica, Av. Camino Santa Teresa 930, Col. Héroes de Padierna, \\ Del. Magdalena Contreras, C.P. 10700 México, CDMx, Mexico. \\ (J-MD-R) E-mail: jdarocha@itam.mx, jmrocha@uvigo.es. ORCID iD: https://orcid.org/0000-0003-3985-8816 \\ ${ }^{2}$ Universidade de Vigo, Escuela de Comercio. Calle Torrecedeira 105, 36208-Vigo, Spain. \\ ${ }^{3}$ Universidade de Vigo, Facultade de Económicas de Vigo. Rúa Leonardo da Vinci, 36310 Vigo, Spain. \\ (JG-C) E-mail: fjgarcia@uvigo.es. ORCID iD: https://orcid.org/0000-0003-3576-6359 \\ ${ }^{4}$ University of the Basque Country (UPV/EHU). FAEII and MacLab. Avd. Lehendakari Aguirre 83, 48015 Bilbao, Spain. \\ (M-JG) (Corresponding author) E-mail: mariajose.gutierrez@ ehu.eus. ORCID iD: https://orcid.org/0000-0003-3074-0854
}

\begin{abstract}
Summary: Unwanted catches can be reduced by improving fishing effectiveness in targeting species and sizes and by banning their sale for human consumption. The landing obligation introduced by the European Union can be seen as a combination of these two measures, and the aim of this paper is to analyse its effects on the Southern Iberian Hake Stock fishery. To this end, reference points for a mixed fishery are computed under the two measures as the steady-state solution of a dynamic optimal management problem. Our results show that measures that improve selectivity obtain better results than sales ban strategies in terms of increasing yields and stocks and reducing discards. In particular, we find that reducing the selectivity parameters by $90 \%$ for the three early ages leads to an almost six-fold increase in the hake yield and lowers the discard rate by more than 20 percentage points. Banning the sale of the two youngest ages also increases hake yield by $21 \%$ and the discard rate by 7 percentage points.
\end{abstract}

Keywords: unwanted catches; selectivity; landing obligation; ban on sale juveniles; age-structured models; European Hake; Southern Iberian Hake.

Mitigación de las capturas no deseadas en la pesquería de la merluza del caladero sur ibérico: Mejora de la tecnología pesquera vs políticas de control de mercado

Resumen: Las capturas no deseadas pueden reducirse mejorando la efectividad a la hora de seleccionar las especies y los tamaños elegidos, así como prohibiendo su venta para el consumo humano. La obligación de desembarco impulsada por la Unión Europea (UE) puede entenderse como una combinación de ambos tipos de medidas. El objetivo de este artículo es analizar los efectos de estos dos tipos de políticas aplicados a la pesquería de la Merluza del Caladero Sur Ibérico. Con este objetivo, se computaron los puntos de referencia asociados a una pesquería mixta para las dos políticas como la solución del estado estacionario de un problema de gestión dinámica óptima. Nuestros resultados muestran que las medidas que mejoran la selectividad pesquera generan mejores resultados que las que prohíben la venta, incrementando la producción y el stock y reduciendo los descartes. En concreto, encontramos que reducir los parámetros de selectividad un $90 \%$ para las tres edades más jóvenes multiplica la producción de merluza por casi 6 , a la vez que reduce la tasa de descartes en más de 20 puntos porcentuales. A su vez, nuestros resultados también muestran que prohibir la venta de las dos edades más jóvenes aumenta la producción de merluza un $21 \%$ incrementando también la tasa de descartes en 7 puntos porcentuales.

Palabras clave: capturas no deseadas; selectividad; prohibición de venta de juveniles; modelos estructurados por edades; merluza europea; Merluza del Caladero Sur Ibérico.

Citation/Como citar este artículo: Da-Rocha J.-M., García-Cutrín J., Gutiérrez M.-J. 2018. Mitigating unwanted catches in the southern Iberian hake stock fisheries: Improving fishing technology vs market control policies. Sci. Mar. 82S1: 63-74. https://doi.org/10.3989/scimar.04739.25A

Editor: F. Maynou.

Received: December 1, 2017. Accepted: April 25, 2018. Published: June 7, 2018.

Copyright: (C) 2018 CSIC. This is an open-access article distributed under the terms of the Creative Commons Attribution 4.0 International (CC BY 4.0) License. 


\section{INTRODUCTION}

A variety of terms are used in the literature related to wastage in fisheries. Unwanted catches can be understood as incidental catch of organisms that cannot be marketed because they have little or no economic value, or because of legal requirements (Maeda et al. 2017). Discards refer to the organisms of both commercial and non-commercial value that are caught during commercial fishing operations and returned to the sea, often dead or dying (Feekings et al. 2012).

Unwanted catches have been regarded as a key issue in commercial fishing worldwide (Kelleher 2005). Most unwanted catches are discarded and returned to the sea with a low survival rate, especially in the case of fish (Revill 2012, Guillen et al. 2014). Discards are influenced by a variety of factors that differ for each species and portion of discards (Feekings et al. 2012). For most species there is greater variability in discard rates across regions than across fisheries, suggesting that a region-by-region approach to discard reduction would be more meaningful (Uhlmann et al. 2014).

In the European Union (EU), discard levels vary considerably from one location and gear to another. For instance, for the Galician fleet discard rates range from insignificant (coastal trolling fleet) to $43.5 \%$ (offshore trawling fleet) of total catches (Vázquez-Rowe et al. 2011). The Nephrops trawl fishery in the Bay of Biscay discards about half of its catches in numbers, of which only $30 \%$ survive (Macher et al 2008). Tsagarakis et al. (2014) found that discards account, on average, for $18.6 \%$ of total catches in the Mediterranean Sea and are concentrated mainly in the bottom and shrimp trawls, despite their relatively low contribution to catches in weight terms. In addition, other factors such as water depth (Sánchez et al. 2004) and fishing intensity (Sánchez et al. 2007) also affect discards in the Mediterranean Sea.

All these concerns about discards were taken into account in the latest reform of the EU Common Fisheries Policy (EU 2013, Article 5), which includes a discard ban called the landing obligation (LO), which requires all catches of stocks subject to a total allowable catch regulation to be kept on board, landed and counted against quotas. This new regulation also states that fish under the legal minimum landing size only can be sold for fishmeal or other products not destined for direct human consumption. Some exemptions are established for protected species, for species with a high survivability and for discards that cannot be easily reduced through selectivity and avoidance measures (de minimis exemptions).

Although the LO will not be fully in force in all EU waters until 2019, its effects have already been studied in light of a bioeconomic modelling framework. For instance, Batsleer et al. (2016) applied the dynamic state variable model proposed in Clark and Mangel (2000) and state that restrictive quotas do not necessarily lead to a reduction in discards when a discard ban is not properly enforced. Prellezo et al. (2016) and Prellezo et al. (2017) use the FLBEIA simulation bioeconomic model (García et al. 2013,
2016) to estimate the effects of the LO on the Basque trawling fleet operating in the Bay of Biscay. Their results are mixed. The LO will probably have a negative short-term effect on the economic performance of the fleet, but at the same time there are likely to be private incentives to improve selectivity to reduce discards. Villasante et al. (2016a) used the stochastic age-structured optimization model developed in Da Rocha et al. (2012a, 2013) to investigate the impact of the LO in the Galician multispecies small-scale gillnet fishery. They found that the LO would result in short- and long-term losses of fishing days and yields. The future yield (catches) under the LO would be only $50 \%$ of catches expected without the LO. In an experimental study, Mortensen et al. (2017) show that relaxing technical regulations combined with proper incentives may help cope with the LO, reducing unwanted catches to some extent without negative effects on economic viability.

Assessing policies that seek to mitigate unwanted catches may help us understand what factors can contribute to the success of the LO. Various policies aim to reduce unwanted catches. Some focus on promoting the adoption of fishing technologies that improve age selectivity and effectiveness in harvesting target species (Catchpole et al. 2006, Kraak et al. 2013). Others focus more on market control by banning the sale or trade of unwanted catches, especially for pelagic species that are taken incidentally as by-catch (Tolotti et al. 2015). In fact, the LO policy promoted by the EU can be seen as a set of new rules that combine measures of this type. On the one hand, the LO compels regulated fisheries to land unwanted catches that could be reduced by using more selective technologies. On the other hand, under the LO catches below the minimum landing size cannot be sold for direct human consumption but can be sold for other uses. This possibility of trading undersized fish for other uses than human food may indirectly stimulate the black market of undersized fish for human food because the price for fish as reduction material is much lower than the price for human consumption (Catchpole et al. 2017). Stakeholders have also expressed alarm, fearing that the implementation of the LO could give rise to a black market for juveniles, thus neutralizing all the efforts made so far by the administration to address this problem (de Vos et al. 2016).

In this article, we study the impacts of two measures aimed at reducing unwanted catches. First, we analyse the impact of age selectivity improvements on catches and discards. Second, we analyse the effects of imposing a ban on sale for different age ranges. To this end, we use a stochastic age-structured optimization model (SASOM). In particular, we compute reference points for a mixed fishery under several scenarios, representing the two measures as the steady-state solutions of a dynamic optimal management problem in which the present value of an economic indicator is maximized (Da Rocha et al. 2010, 2016). Following Da Rocha et al. (2012b), the optimization problem takes into account that species are caught simultaneously, in unselective fishing. The model is applied to the southern Iberian 


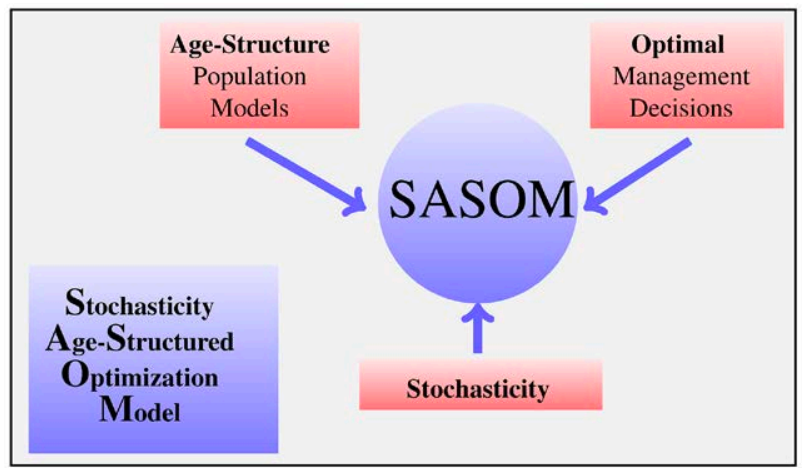

Fig. 1. - The main characteristics of the SASOM approach.

hake stock (SIHS) fishery and the analysis focuses on the effects of these measures on the yield, the stock and the discard rate.

\section{METHODS}

A SASOM approach was used to assess the effects of mitigating the unwanted catches policy. The key aspects of the models that follow a SASOM approach are the following (Fig. 1):

- Optimality: solutions derived from SASOM always represent the optimal responses of agents given the economic and biological settings of the fishery.

- Age-Structured populations: the resource is structured in cohorts, i.e. in groups of fish that have the same age; in most cases, the length of the fish can be used as an indirect indicator of age (Cotter and Pilling 2007).

- Stochasticity: sources of uncertainty generate shocks affecting economic and/or biological aspects of the fishery.

The bioeconomic model that we used is based on the multispecies setting developed in Da Rocha et al. (2012b) which captures the age-structure and the optimization elements of the SASOM approach and can be extended to include the stochastic element by considering the main sources of uncertainty of the fishery. Figure 2 represents the logic of the model. It comprises two main model-boxes. One of them represents the biological aspects of the fishery, and has inputs such as recruitments and parameters representing selectivity, weights, maturity levels and natural mortality levels. The other box represents the economic model, which usually means the managers' decision problem based on economic elements such as the cost and demand functions and the discount rate when the decision is a long-term one. Other social constrains such as the preservation of jobs in fleets can also be considered by the economic model. The managers' decision problem is solved by taking into account the biological model, and as result optimal reference points (fishing mortality levels) are obtained. This optimal decision enables the stock to be evaluated in terms of economic indicators such as the present value of the yield.

The biological part of the model was represented as the standard multispecies age-structured model used for stock assessment. It was assumed that there were $S$ species in the fishery. The stock of species $s=1, \ldots, S$

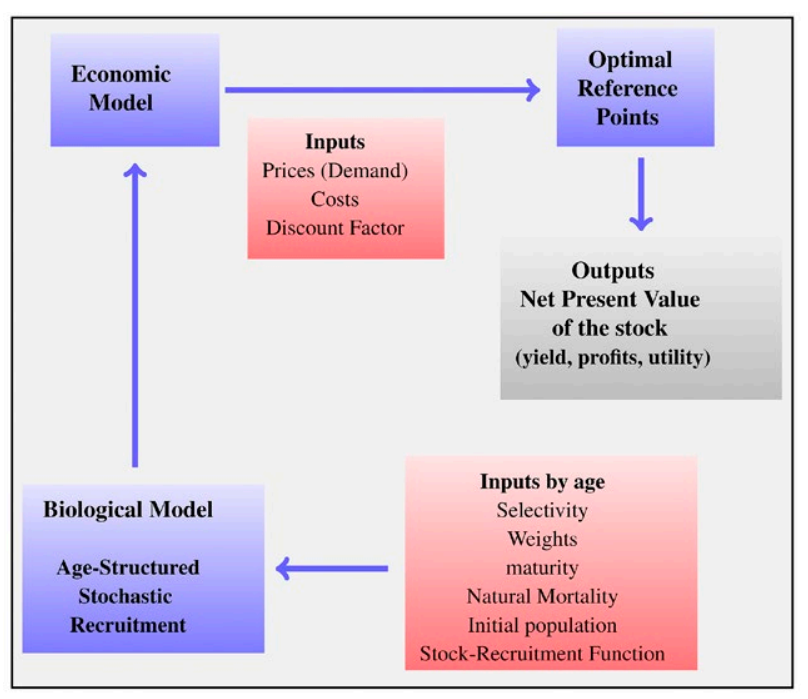

Fig. 2. - Optimal reference points within the SASOM framework.

was broken down into $A_{s}$ cohorts. i.e. in each period there were $A_{s}-1$ initial old cohorts for species $s$ and a new cohort was born.

Let $Z_{s, a, t}$ be the mortality rate that affects the population of species $s$ at age $a$ in period $t$. This mortality rate was decomposed into fishing mortality, $F_{s, a, t}$ and natural mortality, $M_{s, a}$, so $Z_{s, a, t}=F_{s, a, t}+M_{s, a}$. While the fishing mortality rate varied from one period and one age to another, we assumed that natural mortality was constant over periods as the assessment groups tend to do (e.g. ICES 2015, 2016).

We also assumed that all $S$ species were fished simultaneously in relatively unselective fishing operations, representing the catchability by $q_{s}$, and that the landing and discard selection patterns of each cohort of each species, $\bar{p}_{s, a}$ and $\bar{d}_{s, a}$ were constant. Therefore, for each unit of effort, $E_{t}$, the fishing mortality for each age and species was given as $F_{s, a, t}=\left(\bar{p}_{s, a}+\bar{d}_{s, a}\right) q_{s} E_{t}$. This can be understood as a multiproduct technology in which different goods (fish of different ages and species) were caught with the same input (fishing effort, $\left.E_{t}\right)$ in different fixed proportions represented by $\left(\bar{p}_{s, a}+\right.$ $\left.\bar{d}_{s, a}\right) q_{s}$. This fixed proportion approach (Leontief 1944) enabled the fishing mortality multiplier to be defined with no loss of generality as effort $F_{t}=E_{t}$, and the original landing and discard selection pattern, $p_{s, a}=\bar{p}_{s, a} q_{s}$ and $d_{s, a}=\bar{d}_{s, a} q_{s}$, could be rescaled to express the fishing mortality for each age and species as $F_{s, a, t}=\left(\bar{p}_{s, a}+\bar{d}_{s, a}\right)$ $q_{s} E_{t}=\left(p_{s, a}+d_{s, a}\right) F_{t}$.

The population of species was assumed to decrease at an exponential rate in accordance with the mortality rate, $Z_{s, a, t}$. Formally, $N_{s, a+1, t+1}=\mathrm{e}^{-Z_{s, a, t}} N_{s, a, t}$ where $N_{s, a, t}$ represented the abundance of species $s$ for age $a$ at the beginning of time $t$. Notice that by backward substitution $N_{s, a, t}$ could be expressed as a function of recruitment (see Da Rocha et al. 2012b for more details).

Dead fish were classified as dying from natural causes $(M)$, discards $(D)$, or valid catches for sale $(C)$. So the dynamics of the fishery for any age and species could be expressed at any time as $N_{\mathrm{s}, \mathrm{a}, \mathrm{t}}-N_{\mathrm{s}, \mathrm{a}+1, \mathrm{t}+1}=M_{s, a, t}$ $+D_{s, a, t}+C_{s, a, t}$, where 


$$
\begin{aligned}
& M_{s, a, t}=\frac{m_{s, a}}{Z_{s . a . t}}\left(N_{s, a, t}-N_{s, a+1, t+1}\right)=\frac{m_{s, a}}{Z_{s . a . t}}\left(1-e^{Z_{s . a . t}}\right) N_{s, a, t} \\
& D_{s, a, t}=\frac{d_{s, a} F_{t}}{Z_{s . a . t}}\left(N_{s, a, t}-N_{s, a+1, t+1}\right)=\frac{d_{s, a} F_{t}}{Z_{s . a . t}}\left(1-e^{Z_{s . a . t}}\right) N_{s, a, t} \\
& C_{s, a, t}=\frac{p_{s, a} F_{t}}{Z_{s . a . t}}\left(N_{s, a, t}-N_{s, a+1, t+1}\right)=\frac{p_{s, a} F_{t}}{Z_{s . a . t}}\left(1-e^{Z_{s . a . t}}\right) N_{s, a, t}
\end{aligned}
$$

The above expression represents Baranov's equation (Baranov 1918) for valid captures from the point of view of sale without considering discards. We refer to the yield of species $s$ as the sum of the weights of all valid captures of all its ages,

$$
Y_{s, t}=\sum_{a=1}^{A_{s}} \omega_{s, a} C_{s, a, t}=\sum_{a=1}^{A_{s}} \frac{\omega_{s, a} p_{s, a} F_{t}}{Z_{s . a . t}}\left(1-e^{Z_{s . a . t}}\right) N_{s, a, t}
$$

where $\omega_{s, a}$ represents the individual fish weight for age and species $s$. Notice that discard patterns appear as an element of the mortality rate per age and species, $Z_{s, a, t}$, so they influence the fraction of the mortality that determines the yield for sale, $p_{s, a} F_{t} / Z_{s, a, t}$.

The size of a new cohort (recruitment) of species was determined by the stock-recruitment (S-R) relationship proposed by Shepherd (1982),

where

$$
N_{s, 1, t+1}=\frac{\alpha_{s} S S B_{s, t}}{1+\left(S S B_{s, t} / K_{s}\right)^{b_{s}}}
$$

$$
S S B_{s, t}=\sum_{a=1}^{A_{s}} \omega_{s, a} \mu_{s, a} N_{s, a, t}
$$

is the spawning-stock biomass, which depended on the individual fish weight for any age and species, $\omega_{s, a}$, and the maturity fraction, $\mu_{s, a} ; \alpha_{s}, b_{s}$ and $K_{s}$ are parameters with specific values for species $s$; $\alpha_{s}$ represents the slope at the origin of the $\mathrm{S}-\mathrm{R}$ curve of species $s$, which is a measure of the maximum recruitment-per-unit-biomass attainable only at low stock sizes where densitydependent mortality (of pre-recruits) is presumably least; $K_{s}$ measures a threshold of biomass of species $s$ below which the population becomes increasingly vulnerable and the likelihood of collapse is increased; and $b_{s}$ represents the degree of compensation that measures the power of the density-dependent effects to compensate for changes of stock size, particularly at large stock sizes (Shepherd 1982).

In this study, the economic model represented in Figure 1 was synthesized in a management tool that was used to find the reference points (fishing mortalities) that maximized the present value of the total yield of the fishery without considering discards. Formally, the present value of the total yield was defined as the discounted sum of the valid captures, in weight, of all species, that is

$$
Y=\sum_{t=0}^{\infty} \beta^{t} \sum_{s=1}^{S} Y_{s, t}
$$

where $0 \leq \beta \leq 1$ was the discount factor which represented the willingness of the manager (or society) to tradeoff the value of fishing at the current moment against the benefits of increased yields in the future, measured

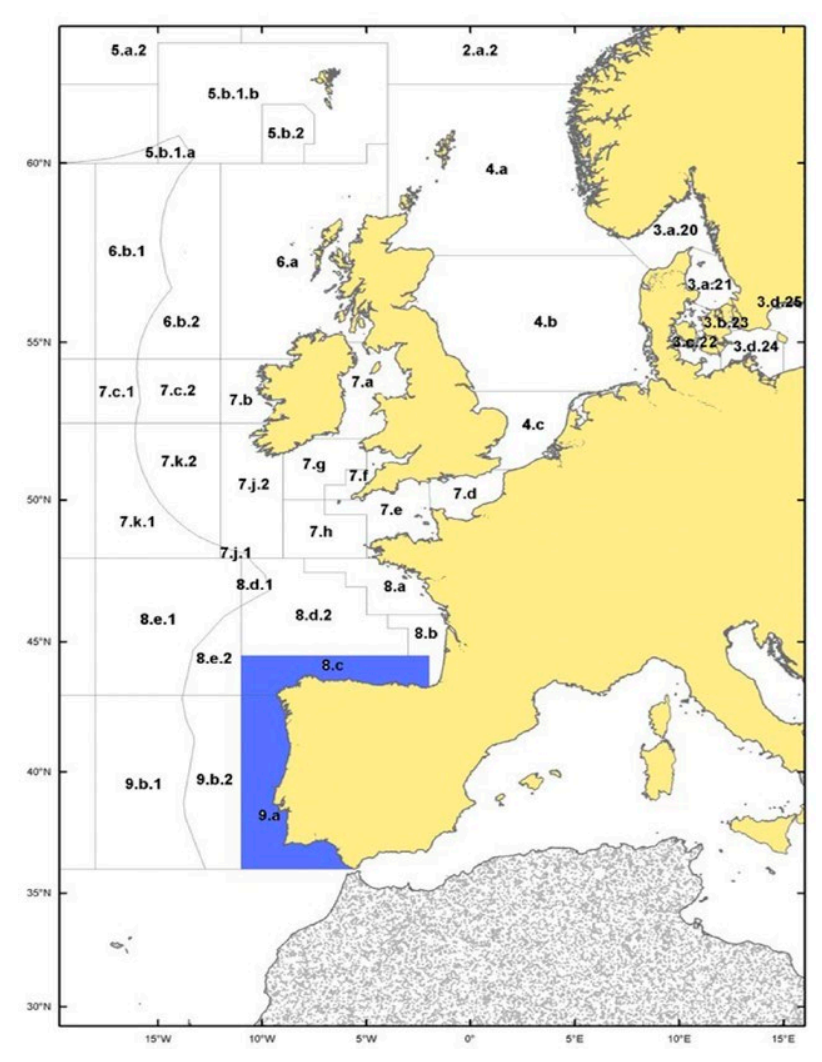

Fig. 3. - The southern Iberian hake stock includes ICES subareas $8 \mathrm{c}$ and $9 \mathrm{a}$ (in blue).

by higher biomass and recruitment. The optimal reference point emerged as the steady-state solution of this dynamic problem. Da Rocha et al. (2012b) proved that this steady-state solution is just a generalization of $F_{m s y}$.

\section{THE SOUTHERN IBERIAN HAKE STOCK}

The model presented in previous Section is applied to the SIHS in order to study the impacts of measures aimed at reducing unwanted catches in that fishery.

\section{Overview of the SIHS fishery}

The northern limit of the SIHS is the SpanishFrench border and the southern limit is the Straits of Gibraltar (see Fig. 3). The SIHS fishery is managed with the advice of the International Council for the Exploration of the Sea (ICES), and it includes all fisheries in subareas 8c and 9a. The SIHS is a mixed fishery in which European hake (Merluccius merluccius) is caught with other demersal species (e.g. megrim, monkfish and Nephrops) and pelagic species (e.g. blue whiting, sardine and horse mackerel) by the Spanish and Portuguese fleets (trawls, gillnetters, longliners and artisanal fleets). Spain accounts for most of the landings. Total landings and discards were $12443 \mathrm{t}$ and $2313 \mathrm{t}$, respectively, in 2016. Total catches in 2016 were 5\% higher than in 2015. The fishery is managed by total allowable catches, effort control and technical measures. On the basis of the transition to the maximum 
sustainable yield approach, ICES advised that catches for hake in the SIHS should be no more than $8049 \mathrm{t}$ in 2017. Since this stock was only partially under the LO in 2016, ICES was not in a position to advise on landings corresponding to the advised catch. Nevertheless, the agreed total allowable catch for hake was $10674 \mathrm{t}$ in 2016 and $10520 \mathrm{t}$ in 2017 (ICES 2017b).

A recovery plan for the SIHS was implemented in 2006 (EC 2005). This plan aims to rebuild the stock to within safe biological limits. However, ICES considers that the spawning-stock biomass $(S S B)$ target of the recovery plan $(35000 \mathrm{t})$ is no longer valid and the stock has returned to a healthy state. This regulation also includes effort management by limiting days at sea, which are updated every year. The effort from fishing trips whose hake catch is less than $8 \%$ of the total catch is excluded from the regulation. Technical measures applied to this stock include (i) a minimum landing size of $27 \mathrm{~cm}$, (ii) protected areas, and (iii) a minimum mesh size. These measures are set, depending on areas and gears, by several national regulations (ICES 2017b).

In this study we focus on European hake (Merluccius merluccius) as the main target species of the SIHS, in addition to other demersal species with a secondary role such as megrim (Lepidorhombus whiffiagonis, MGW), four-spot megrim (Lepidorhombus boscii, MGB) and monkfish (Lophius piscatorius, MON). Captures of hake in the SIHS are expected to be 3.5 to 4 times the captures of the other three species together in 2017, depending on the type of assessment (single or mixed) under which the forecasting is made (ICES 2017c). Pelagic species such as horse mackerel and blue whiting are not included in the study because their contribution to catches and revenues of the fleets is less significant. Nevertheless, they could play an important role under the $\mathrm{LO}$ regulation because they can become a choke species for the fleets: since the quota for these species are low, a vessel may stop fishing too early because the quota have been reached, even if there are available quota for other species (Schrope 2010).

\section{Parameterizing the SIHS fishery}

The parameterization used for the age-structured population is the same as that used in the ICES Working Group on the Assessment of Southern Shelf Stocks of Hake, Monk, and Megrim (ICES 2015), as presented in Appendixes 1 and 2. The assessment of the SIHS depends on whether or not discards are included in the analysis (Fernández et al. 2010), so discard patterns are taken into account for hake.

Hake recruitments were modelled using the Shepherd (1982) stock-recruitment relationship, which was estimated from recruitment and $S S B$ data for 1978-2006. This fit produced $\alpha=14.774, K=12134.22$ and $b=1.604$. For the secondary species, the expected recruitment is considered as constant over time. In particular, recruitment (in thousands) is 2504 for MGW, 24016 for MGB and 855 for MON.

Reference points for single and mixed fisheries are computed as the steady-state solution of a dynamic op- timal management problem in which the yield is maximized. The optimization problem takes into account that (i) species are caught simultaneously in unselective fishing operations; and (ii) there is intertemporal discounting equal to $\beta=0.95$ (i.e. an interest rate close to 5\%). See Da Rocha et al. (2012b) for a similar approach with the northern Iberian stock of hake.

\section{POLICIES FOR MITIGATING UNWANTED CATCHES IN THE SOUTHERN IBERIAN HAKE STOCK}

When the model presented in Section 2 had been parameterized for the SIHS, it was applied to study the impacts of two measures intended to reduce unwanted catches. Both measures were analysed first under the ceteris paribus criteria, and then the results of combining the two measures were studied.

\section{Improving fishing age selectivity}

It is assumed that good fishery management requires fishing gears to catch large adult fish while allowing small juveniles to escape (Armstrong et al. 1990). In this section we show how the SIHS fishery would change if the selectivity of early ages were improved, ceteris paribus. Our study thus focuses on age (or size) selectivity improvements.

To this end, an age-species specific parameter, $0 \leq \gamma_{s, a} \leq 1$, is introduced into the mortality rate and into the Baranov yield equation that quantifies the valid catches, in weight, for sale. Formally, the yield of species $s$ is calculated as

$$
Y_{s, t}=\sum_{a=1}^{A_{s}} \frac{\left(1-\gamma_{s, a}\right) \omega_{s, a} p_{s, a} F_{t}}{Z_{s, a, t}}\left(1-e^{-Z_{s, a, t}}\right) N_{s, a, t}
$$

where

$$
Z_{s, a, t}=M_{s, a}+\left(1-\gamma_{s, a}\right)\left(d_{s, a}+p_{s, a}\right) F_{t}
$$

and $\gamma_{s, a}$ represents the reduction, in percentage terms, in the selectivity parameter of age and species $s . \gamma_{s, a}=0$ represents the status quo, so applying $\gamma_{s, a}=0.30$ means that with the same fishing effort the fishing mortality for species $s$ and age $a$ will be $70 \%$ of the status quo fishing mortality, i.e. $30 \%$ lower. Thus, higher $\gamma$ 's in young ages can be understood as indicative of more age selective technologies.

Including the parameter $\gamma_{s, a}$ in the yield and the mortality as expressed in Equations 2 and 3 can be seen as a generalization of the procedure used in Heikinheimo et al. (2006). In this article, selectivity is affected by a multiplicative factor that takes the value of one when selectivity remains unchanged or zero when selectivity is complete. In our analysis, $\gamma_{s, a}$ can take any value between zero and one representing the possibility of uncomplete selectivity change.

Table 1 illustrates the results of improving age selectivity by using $\gamma_{s, a}=0.90$. The mixed nature of the fishery means that a single reference point needs to be calculated for the management of the resource. The first row in Table 1 shows the optimal fishing mortality 
Table 1. - Improving age selectivity by age ranges in the SIHS fishery. Reference points, $F$, represent the fishing mortality that maximizes the present value of the total yield of the fishery as defined by Equation 1 using a discount factor $\beta=0.95$. Yield represents the stationary value of the valid catches (without discards) as defined by Equation 2 under the optimal $F$. The status quo represents the situation in which the selectivity parameter does not change $\left(\gamma_{s, a}=0\right)$. Values in bold represent the best scenario for each variable.

\begin{tabular}{|c|c|c|c|c|c|c|c|}
\hline \multicolumn{8}{|c|}{ Reduction in age selectivity parameters: $\gamma_{s, a}=0.90$} \\
\hline & \multirow{2}{*}{ Status quo } & \multicolumn{6}{|c|}{ Age range policy application } \\
\hline & & 0 & $0-1$ & $0-2$ & $0-3$ & $0-4$ & $0-5$ \\
\hline$F$ & 0.70 & 0.73 & 1.11 & 1.66 & 1.88 & 2.12 & 2.61 \\
\hline Total yield for all age classes $(\mathrm{t})$ & & & & & & & \\
\hline $\begin{array}{l}\text { HKE } \\
\text { MGW }\end{array}$ & 2910 & 4309 & 13707 & 16783 & 15760 & 13824 & 9779 \\
\hline MGW & 147 & 147 & 150 & 151 & 151 & 150 & 150 \\
\hline MGB & 1353 & 1354 & 1359 & 1349 & 1345 & 1341 & 1333 \\
\hline MON & 1066 & 1055 & 888 & 624 & 532 & 446 & 302 \\
\hline \multicolumn{8}{|l|}{ Species $S S B(\mathrm{t})$} \\
\hline $\mathrm{HKE}$ & 2686 & 3880 & 13339 & 23629 & 26928 & 24087 & 12332 \\
\hline MGW & 553 & 546 & 471 & 380 & 348 & 317 & 261 \\
\hline MGB & 4867 & 4814 & 4202 & 3498 & 3263 & 3039 & 2634 \\
\hline $\mathrm{MON}$ & 2673 & 2551 & 1363 & 529 & 364 & 246 & 106 \\
\hline \multicolumn{8}{|l|}{ Change from status quo } \\
\hline Yield HKE & 1.00 & 1.48 & 4.71 & 5.77 & 5.42 & 4.75 & 3.36 \\
\hline Total yield & 1.00 & 1.20 & 2.50 & 2.88 & 2.71 & 2.41 & 1.80 \\
\hline Hake discards / hake yield & 0.31 & 0.31 & 0.14 & 0.10 & 0.10 & 0.12 & 0.21 \\
\hline
\end{tabular}

in the status quo as well as in the scenarios analysed. A total of six scenarios were simulated. The first scenario corresponds to reducing selectivity of the first age class, the second scenario to the reduction in the first two age classes, and so on to complete all six age classes of the hake. The results show that the optimal fishing mortality, i.e. the $F$ that maximizes the present value of total yield of the fishery, is $F=0.70$ in the status quo. When the selectivity parameter is reduced by $90 \%$ for age 0 , the optimal reference point increases to $F=0.73$; when this reduction is extended to ages 0 and 1 the optimal reference points increases to $F=1.11$, and so on.

The results show that the highest yield for the main species (hake) occurs when selectivity is improved for ages 0,1 and 2, in which the hake yield is 5.77 times greater than in the status quo scenario. However, the highest $S S B$ is found when the improvement in selectivity also includes age 3 . In this case, the yield of hake is 5.42 times greater than in the status quo.

Another prominent result is that hake becomes more important in the fishery in terms of yield and $S S B$ in comparison with the secondary species when the selectivity improves optimally. In the status quo, hake yield and $S S B$ represent $53 \%$ and $25 \%$ of total yield and $S S B$, respectively; however, if selectivity improves for the age range $0-2$, the yield and $S S B$ of hake reach $89 \%$ and $85 \%$ of total yield and $S S B$, respectively.

It is also worth mentioning that our results with respect to yield are in the range of the catch options set out for 2018 in the "max" and "min" scenarios of the ICES single-stock advice for Atlantic Iberian waters (ICES 2017a). The "min" scenario is based on the assumption of a strictly implemented discard ban and the "max" scenario represents the upper bound of potential catches because it assumes all fleets continue fishing until all their stock quotas are exhausted. Only the yield of monkfish would be slightly lower in our scenario than in the "min" scenario of ICES, highlighting the fact that the monkfish SSB would decrease dramatically in our projections from 2551 to $529 \mathrm{t}$, which is a level even lower than its yield. This result may be driven by the constant recruitment assumption for the monkfish, but this reduction of the $S S B$ is crucial and may put monkfish stock in a position of danger. It would be necessary to fix low quotas for monkfish otherwise it would likely become a choke species, causing the fleet to stop fishing too early even if there are available quota for other species.

Overall, reducing the selectivity parameters by $90 \%$ for the three lower ages leads to the greatest improvements in terms of hake yield compared with the status quo scenario. Moreover, hake discards are significantly more than 20 percentage points lower than the status quo.

This analysis was repeated for other reductions of the age selectivity parameters. Table 2 shows some of the results for the sensitivity analysis. The main conclusion is that only when age selectivity changes significantly are the results positive in terms of increasing yield and reducing discards. This leads to the conclusion that a unless high age selectivity level is achieved, it is better not to incorporate new fishing technologies. The basic reasoning for this result is that in this fishery small changes in the age selectivity do not improve the escapement of juveniles enough to increase the stock of the older ages in the future. The results are summarized in Figure 4 , where the changes in hake yield with respect to

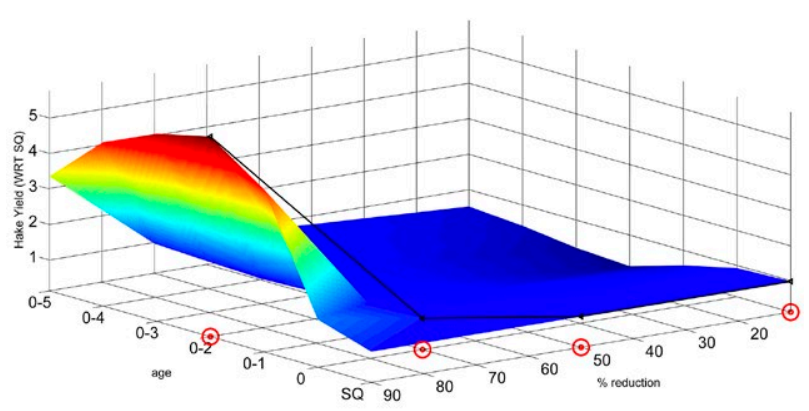

Fig. 4. - Impact on yield of hake in comparison with the status quo as age selectivity improves. Red labels show the optimal age range application for reductions of $90 \%, 70 \%, 50 \%$ and $10 \%$ in the selectivity parameters. The status quo (SQ) represents the situation with zero reduction in the selectivity parameters. 
Table 2. - Improving age selectivity. Sensitivity analysis. Hake yield represents the stationary value of the hake catches (without discards) as defined by Equation 2. Total yield represents the stationary value of the sum of catches, in weight, of all species (without discards). All yield values are calculated for the optimal $F$ under each scenario. The status quo represents the situation in which the selectivity parameter does not change $\left(\gamma_{s, a}=0\right)$. Values in bold represent the best scenario for each variable.

\begin{tabular}{|c|c|c|c|c|c|c|c|}
\hline \multirow{2}{*}{ Reduction selectivity parameter $(\gamma)$} & \multirow{2}{*}{ Status quo } & \multicolumn{6}{|c|}{ Age range policy application } \\
\hline & & 0 & $0-1$ & $0-2$ & $0-3$ & $0-4$ & $0-5$ \\
\hline \multicolumn{8}{|l|}{ Change from status quo. Hake yield } \\
\hline 0.90 & 1.00 & 1.48 & 4.71 & 5.77 & 5.42 & 4.75 & 3.36 \\
\hline 0.70 & 1.00 & 1.01 & 0.98 & 0.89 & 0.83 & 0.90 & 0.97 \\
\hline 0.50 & 1.00 & 0.98 & 0.85 & 0.73 & 0.73 & 0.80 & 0.85 \\
\hline 0.10 & 1.00 & 0.94 & 0.59 & 0.13 & 0.22 & 0.41 & 0.53 \\
\hline \multicolumn{8}{|l|}{ Change from status quo. Total yield } \\
\hline 0.90 & 1.00 & 1.20 & 2.50 & 2.88 & 2.71 & 2.41 & 1.80 \\
\hline 0.70 & 1.00 & 1.02 & 1.02 & 0.96 & 0.91 & 0.97 & 1.03 \\
\hline 0.50 & 1.00 & 0.98 & 0.90 & 0.82 & 0.83 & 0.87 & 0.91 \\
\hline 0.10 & 1.00 & 0.96 & 0.73 & 0.43 & 0.49 & 0.62 & 0.70 \\
\hline \multicolumn{8}{|l|}{ Hake discards / hake yield } \\
\hline 0.90 & 0.31 & 0.31 & 0.14 & 0.10 & 0.10 & 0.12 & 0.21 \\
\hline 0.70 & 0.21 & 0.18 & 0.22 & 0.24 & 0.24 & 0.23 & 0.21 \\
\hline 0.50 & 0.21 & 0.21 & 0.26 & 0.27 & 0.26 & 0.25 & 0.24 \\
\hline 0.10 & 0.24 & 0.24 & 0.32 & 0.34 & 0.32 & 0.31 & 0.30 \\
\hline
\end{tabular}

the status quo are plotted for the reductions in age selectivity parameters and the age ranges over which those reductions are applied.

The results presented show the effects of improving age selectivity only on the yield but not on the profits of the fishery. To calculate profits we would need to know the relative prices of the species and the cost of improving the age selectivity. Prices could be easily introduced in the analysis. In fact, other studies have considered that prices of the secondary species of this fishery are $60 \%$ greater than the price of the main species (García et al. 2016). With respect to the cost of age selectivity improvements, it is well accepted that some can be made without any financial costs. For instance, spatiotemporal measures such as changes in the fishing area or fishery closures are not expensive in terms of operational costs, although they may involve a reduction in the catches in the short term (Dunn et al. 2011). However, most experts consider that in many cases, including small-scale fisheries, age selectivity is difficult to improve without incurring high costs when it requires modifications and adaptations of the current fishing technology (Villasante et al. 2016b). In any event, the increase in long-term yield achieved by improving age selectivity can be seen as an upper bound for the cost of incorporating the new technologies into standard harvesting operations.

\section{Policy for a ban on the sale of juveniles}

Unwanted catches can be reduced through market control policies that ban their sale (Tolotti et al. 2015). In this section we show how the SIHS would change if the sale of some age ranges were banned, ceteris paribus. To that end, we took the ban into account in the Baranov yield equation. For instance, if the ban on sales is imposed for ages $a=1,2, \ldots j$, the yield of species is calculated as

$$
Y_{s, t}=\sum_{a=j+1}^{A_{s}} \frac{\omega_{s, a} p_{s, a} F_{t}}{Z_{s, a, t}}\left(1-e^{-Z_{s, a, t}}\right) N_{s, a, t}
$$

Captures of ages $a=1,2, \ldots j$ are banned for sale and it is implicitly assumed that they are discarded dead to the sea.
The status quo scenario is the situation in which all captures can be sold, even the youngest ones. The selectivity parameters do not vary during the analysis; they are the same for all species and ages as those in the status quo scenario. This means that for a given fishing effort valid captures for sale will decrease and discards will increase as the ban is extended to more ages compared with the status quo.

A total of six scenarios were simulated. Each scenario represents a situation in which the ban on sales affects a particular early age range. The first scenario corresponds to a ban of sale of the first age class, the second scenario to the ban of the sale of the first two age classes, and so on until the ban affects all six age classes of the hake. In each scenario, the only change with respect to the status quo scenario is that the yield function does not include the yield for early ages, as in Equation 4. This means that the reference point $(F)$ that maximizes the present value of yield in the steady state varies as we consider scenarios with different age ranges. These changes in the optimal reference point also lead to differences in the $S S B$ and in the discard ratio in the scenarios studied for the sales ban.

Table 3 illustrates the results of banning the sale of juveniles for the scenarios simulated. The first row shows the optimal reference point for each scenario. In the status quo, which represents the situation in which all captures can be sold, the optimal reference point is $F=0.70$. When the sale of juveniles of age 0 is banned, the optimal reference point stays the same because in the status quo those fishes (fish in their first year of life after hatching) are hardly caught; when this ban is extended to ages 0 and 1 the optimal reference point decreases to $F=0.64$, and so on. The more ages that are covered by the ban in the market, the lower is the fishing mortality applied to the fishery.

The results show that banning the sale of juveniles of ages 0 and 1 leads to the highest improvements in hake yield (up 21\%) and total yield (up 11\%) compared with the status quo scenario. However, these increases are much lower than the increases caused by the selectivity improvements (see Table 1). As expected, the highest $S S B$ is found when the sale ban affects all ages because this is equivalent to the recov- 
Table 3. - Effects on the SIHS fishery of a ban on sales of juveniles. Yield of each species represents the stationary value of the catches in weight (without discards) as defined under the ban on sale scenario (Eq. 4). Total yield represents the stationary value of the sum of valid catches of all species (without discards). All the values are calculated for the optimal $F$ under each scenario. The status quo scenario is the situation in which all captures can be sold. Values in bold represent the best scenario for each variable.

\begin{tabular}{|c|c|c|c|c|c|c|c|}
\hline & \multirow{2}{*}{$\begin{array}{l}\text { Status } \\
\text { quo }\end{array}$} & \multicolumn{6}{|c|}{ Age range policy application } \\
\hline & & 0 & $0-1$ & $0-2$ & $0-3$ & $0-4$ & $0-5$ \\
\hline$F$ & 0.70 & 0.70 & 0.64 & 0.48 & 0.38 & 0.32 & 0.28 \\
\hline \multicolumn{8}{|l|}{ Total yield for all age classes $(\mathrm{t})$} \\
\hline HKE & 2910 & 2912 & 3513 & 2137 & 840 & 294 & 97 \\
\hline MGW & 147 & 146 & 129 & 102 & 71 & 30 & 14 \\
\hline MGB & 1353 & 1353 & 1348 & 1256 & 987 & 632 & 300 \\
\hline MON & 1066 & 1066 & 1072 & 1026 & 865 & 652 & 457 \\
\hline Species SSB (t) & 2686 & 2689 & 4437 & 8411 & 10655 & 12112 & 13202 \\
\hline MGW & 553 & 553 & 565 & 600 & 621 & 635 & 645 \\
\hline MGB & 4867 & 4867 & 4971 & 5268 & 5450 & 5570 & 5659 \\
\hline MON & 2673 & 2674 & 2920 & 3674 & 4174 & 4515 & 4775 \\
\hline \multicolumn{8}{|l|}{ Change from status quo } \\
\hline Yield HKE & 1.00 & 1.00 & 1.21 & 0.73 & 0.29 & 0.10 & 0.03 \\
\hline Total yield & 1.00 & 1.00 & 1.11 & 0.84 & 0.50 & 0.29 & 0.08 \\
\hline Hake discards / hake yield & 0.31 & 0.31 & 0.38 & 0.88 & 2.39 & 6.93 & 21.04 \\
\hline
\end{tabular}

Table 4. - Pure vs mixed sales ban policies. Pure policy corresponds to scenarios in which fish under the age range are banned for sale. Mixed policy corresponds to scenarios in which the ban on sale is applied simultaneously with an improvement in selectivity that represents a $90 \%$ reduction in fishing mortality. Yield results refer to valid captures, in weight, for sale without considering discards. The status quo situation represents the situation in which all captures can be sold and there are no selectivity improvements. Values in bold represent the best scenario for each variable.

\begin{tabular}{|c|c|c|c|c|c|c|c|}
\hline \multirow{2}{*}{ Reduction selectivity parameter $(\gamma)$} & \multirow{2}{*}{ Status quo } & \multicolumn{6}{|c|}{ Age range policy application } \\
\hline & & 0 & $0-1$ & $0-2$ & $0-3$ & $0-4$ & $0-5$ \\
\hline \multicolumn{8}{|l|}{ Change from status quo. Yield } \\
\hline 0.00 (Pure policy) & 1.00 & 1.00 & 1.21 & 0.73 & 0.29 & 0.10 & 0.03 \\
\hline 0.90 (Mixed policy) & 1.00 & 1.06 & 1.54 & 1.04 & 0.51 & 0.24 & 0.11 \\
\hline \multicolumn{8}{|l|}{ Change from status quo. Total yield } \\
\hline 0.00 (Pure policy) & 1.00 & 1.00 & 1.11 & 0.83 & 0.50 & 0.29 & 0.16 \\
\hline 0.90 (Mixed policy) & 1.00 & 1.03 & 1.28 & 0.99 & 0.62 & 0.36 & 0.19 \\
\hline \multicolumn{8}{|l|}{ Hake discards / hake yield } \\
\hline 0.00 (Pure policy) & 0.31 & 0.31 & 0.38 & 0.88 & 2.39 & 6.93 & 21.04 \\
\hline 0.90 (Mixed policy) & 0.31 & 0.31 & 0.35 & 0.67 & 1.36 & 2.74 & 5.44 \\
\hline
\end{tabular}

ery of the fishery after a closure. Rather than improving selectivity measures, the sale ban policy increases the discards rate in comparison with the status quo (up 7 percentage points when the ban applies to the sale of ages 0 and 1 ). This result is intuitive: since discards do not entail any cost for fishers and the fishing technology does not change, the optimal harvest consists in catching larger amounts as the ban covers more ages, even though only a small percentage of them will fulfil the requirement for sale.

This analysis of the sales ban measure is supplemented by the possibility of improving selectivity simultaneously. Table 4 illustrates the results of both measures for hake yield, total yield and the discards/yield ratio for hake in comparison with the status quo, a situation in which all captures can be sold. The figures shown in the first row of the three boxes correspond to the results of applying a pure sales ban, so they are the same as the results that appear in the lower box of Table 3 . The figures in the second row of the three boxes correspond to the results of applying a mixed policy in which the ban on sales is applied simultaneously with an improvement in selectivity that represents a $90 \%$ reduction in fishing mortality. The choice of this particular selectivity improvement is based on the sensitivity analysis shown in Table 2, which shows that, ceteris paribus, only significant changes in the selectivity parameters $\left(\gamma_{s, a}=0.9\right)$ lead to positive results increasing yield and reducing discards when there are no sale restrictions. Therefore, we think that a mixed policy with a $90 \%$ reduction in fishing mortality is the most suitable to be compared with the pure policy.

When the two measures are compared, the following can be observed:

- The mixed policy leads to significantly higher increases than the pure sales ban in the hake yield and total yield than in the status quo for all age range scenarios.

- Both measures lead to a higher discard/yield ratio for hake than in the status quo scenario, and the extent of the rise increases as the age range is extended. However, in all scenarios the discard rate is lower for the mixed policy than for the pure policy because it involves an improvement in the selectivity.

- For both measures, the best results in terms of hake yield and total yield appear when the sales ban applies for ages 0 and 1 .

\section{DISCUSSION}

The reform of the Common Fisheries Policy of 2013 was aimed at gradually eliminating the wasteful practice of discarding through the introduction of the LO. This radical change in fisheries management aims to improve fishing behaviour through improvements in selectivity and other measures. The LO requires all the catches of stocks subject to a total allowable catch regulation to be kept on board, landed and counted against quotas. Moreover, undersized fish cannot be marketed 
for direct human consumption purposes, while prohibited species (e.g. basking shark) cannot be retained on board and must be returned to the sea.

We implemented two measures for reducing unwanted catches in the SIHS fishery. First, we studied the impact on the fishery when age selectivity is improved. Second, we studied the effects of imposing a ban on the sale of juveniles. Both measures are in line with the European legislation that explicitly considers pilot projects on gears to increase selectivity and minimum conservation reference sizes as measures to be taken into account for the conservation and sustainable exploitation of marine resources (EU 2013, Article 7). More particularly, the LO considers that minimum conservation reference sizes may be established to protect juveniles of marine organisms (EU 2013, Article 15, point 10). Furthermore, the EU has allocated structural funds, such as the European Maritime and Fisheries Fund (EMFF, EU 2014), which can be used to support small-scale coastal fishermen to finance up to $80 \%$ of the cost of investment in new gear to improve selectivity and minimize unwanted catches (DirectorateGeneral for Maritime Affairs and Fisheries (EC) 2017).

With respect to the first measure, our results show that reducing the selectivity parameters by $90 \%$ for the three early ages leads to the highest improvements in terms of yield of hake, total yield and hake discards compared with the status quo scenario. In particular, hake yield increased almost six-fold and discards of hake fell more than 20 percentage points in comparison with the status quo.

However, our study also shows that only when age selectivity changes significantly are the results positive in terms of increased yield and reduced discards. This finding is consistent with the results of Mytilineou et al. (1998) and Prellezo et al. (2017), which show that large increases in the minimum mesh size are necessary to achieve significant impacts on biological and/ or economic variables. This result may lead to the discouraging conclusion that unless new fishing devices are really selective in targeting sizes of species caught, it is better not to adopt them. Therefore, testing the effectiveness of new fishing practices and gear devices is an essential step towards adopting new solutions to improve selectivity. This recommendation is in agreement with that of Kennelly and Broadhurst (2002), who propose a five-step framework for solving by-catch fishery problems that includes testing the alternative techniques in field experiments as one of the stages.

The scenarios analysed for the age selectivity improvements should be understood as hypothetical because it will not be possible to implement them with the available fishing technology. Even thinking in the future, it is difficult to believe that technological advances may lead to these "ideal" situations. Selectivity improves only for a particular range of ages but not for the remaining ages, and the improvement of age selectivity is the same, in percentage terms, for all the species caught in this mixed fishery (Table 1). Nevertheless, we think that these scenarios may be of interest because they demonstrate how fishery trends change as age selectivity improves.
In the real world, several fishing practices and gear solutions have been proposed and tested to enhance age selectivity. However, the effectiveness of these modifications are gear- and fishery-specific (Broadhurst et al. 2007). For instance, some studies show that squaremesh codend improves age selectivity compared with diamond-mesh codend of a similar size in a variety of trawl fisheries (Kayka et al. 2009, Gorelli et al. 2017). It has also been proved that the T90 netting (a standard codend mesh turned 90 degrees) significantly increases the selectivity for some species in Northern European trawl fisheries (Herrmann et al. 2007, Bayse et al. 2016) and in the Mediterranean Sea (Deval et al. 2006, Tokaç et al. 2014). Square-mesh panels and escape windows have also shown great potential for improving selectivity in some trawl fishery (Madsen et al. 2002), although the results are not so positive for others (Alzorriz et al. 2016).

The modelling approach used for the simulations in the present article is generic and can be applied to any fishery under any selectivity scenario. This means that once new fishing practices or devices have been developed, new age selectivity parameters will be available for simulating specific scenarios. Our study can therefore be seen as an additional contribution to the studies that have investigated the costs and benefits of age-selective fishing technologies [see Suuronen and Sardà (2007) for a compendium].

Another shortcoming of our analysis is that it does not take into account the cost of modifying and adapting the fishing technology for improving age selectivity. This is a common feature of the few studies that analyse the cost-benefit of a selectivity change (Heikinheimo et al. 2006, Macher et al. 2008). Certainly, selectivity can be improved without much cost by simply making new spatiotemporal decisions (Dunn et al. 2011). However, most experts consider that it is difficult to improve selectivity without incurring high costs when doing so requires modifications and adaptations of the current fishing technology (Villasante et al. 2016b). Nevertheless, the increase yield resulting in our analysis from improving age selectivity can be seen as an approximation to the upper bound for the cost of incorporating the new technology into standard harvesting operations.

With respect to the policy for a ban on the sale of juveniles, our results show that banning the sale of ages 0 and 1 leads to the highest improvements in hake yield ( $21 \%$ up) and total yield (11\% up) compared with the status quo scenario. Rather than improving selectivity measures, this policy raises discards by seven percentage points. Since discards do not involve any cost, fishers capture larger amounts as the ban covers more ages, even though only a small percentage of them can be sold under the ban. These positive results for hake yield and total yield are reinforced when the sales ban is accompanied by improvements in selectivity. However, the improvements are not sufficient to revert the rise in the discard rate.

Comparing the two policies, we can conclude that measures that improve selectivity give better results than sales ban strategies in terms of increasing yields and stock and reducing discards. 
The model used to carry out this study falls within the framework of the SASOM approach, which allows biological and economic aspects of the fishery to be incorporated simultaneously considering potential sources of uncertainty (Da Rocha and Gutiérrez 2011). The extended information about the SIHS provided by ICES enables to include details of the biological elements (ICES 2015) although with some limitations, such as the recruitment of the secondary species, which was assumed constant. Moreover, the available information is not sufficient to confidently include a cost function for the fishery or to consider social concerns such as the preservation of jobs in fleets. All these constraints limit the analysis, and the conclusions must therefore be taken with caution.

Another weakness of our analysis is that the model does not consider that species can have different quotas, and this could lead to the "choke species effect" preventing the fleet from taking advantage of its fishing opportunities under the LO. This is especially important if any of the species have a very small quota (García et al. 2016) or if any of them show an unfavourable length distribution of the captures, with most catches under legal minimum size (Prellezo et al. 2017). Further research on these issues would be very advisable to complete the analysis.

\section{ACKNOWLEDGEMENTS}

We thank three anonymous referees and the editor for their useful comments, which helped improve the article. This work was funded by the European Commission as part of the MINOUW project (H2020SFS-2014-2, number 634495) and by the Spanish Ministry of Economy, Industry and Competitiveness (ECO2016-78819-R, AEI/FEDER, UE). JMDR and JGC gratefully acknowledge the financial support from the Xunta de Galicia (GRC 2015/014 and ECOBAS). MJG also acknowledges the financial support from the Basque Government (MacLab IT-793-13).

\section{REFERENCES}

Alzorriz N., Arregi L., Herrmann B., et al. 2016. Questioning the effectiveness of technical measures implemented by the Basque bottom otter trawl fleet: Implications under the EU landing obligation. Fish. Res. 175: 116-126. https://doi.org/10.1016/j.fishres.2015.11.023

Armstrong D., Ferro R., MacLennan D.N., et al. 1990. Gear selectivity and the conservation of fish. J. Fish Biol. 37: 261-262. https://doi.org/10.1111/j.1095-8649.1990.tb05060.x

Baranov F. 1918. On the question of the biological basis of fisheries. Institute for Scientific Ichthyological Investigations, Proceedings 1: 81-128.

Batsleer J., Rijnsdorp A., Hamon K., et al. 2016. Mixed fisheries management: Is the ban on discarding likely to promote more selective and fuel efficient fishing in the Dutch flatfish fishery? Fish. Res. 174: 118-128. https://doi.org/10.1016/j.fishres.2015.09.006

Bayse S.M., Herrmann B., Lenoir H., et al. 2016. Could a T90 mesh codend improve selectivity in the Belgian beam trawl fishery? Fish. Res. 174: 201-209. https://doi.org/10.1016/j.fishres.2015.10.012

Broadhurst M., Kennelly T., Gray C. 2007. Strategies for improving the selectivity of fishing gears. In: Kennelly S. (ed.), By-catch Reduction in the World's Fisheries. Springer, Cronulla, Australia, pp. 1-21.

https://doi.org/10.1007/978-1-4020-6078-6_1
Catchpole T., Frid C., Gray T. 2006. Resolving the discard problem. A case study of the English Nephrops fishery. Mar. Policy 30: 821-831.

https://doi.org/10.1016/j.marpol.2006.04.002

Catchpole T., Ribeiro-Santosa A., Mangib S., et al. 2017. The challenges of the landing obligation in EU fisheries. Mar. Policy 82: 76-86. https://doi.org/10.1016/j.marpol.2017.05.001

Clark C., Mangel M. 2000. Dynamic state variable models in ecology: methods and applications. Oxford Univ. Press, Oxford, UK.

Cotter A., Pilling G. 2007. Landings, logbooks and observer surveys: improving the protocols for sampling commercial fisheries. Fish Fish. 8: 123-152 https://doi.org/10.1111/j.1467-2679.2007.00241.x

Da Rocha J.M., Gutiérrez M.J. 2011. Lessons from the northern hake long-term management plan: Could the economic assessment have accepted it? ICES J. Mar. Sci. 68: 1937-1941. https://doi.org/10.1093/icesjms/fsr105

Da Rocha J.M., Cerviño S., Gutiérrez M.J. 2010. An endogenous bio-economic optimization algorithm to evaluate recovery plans: an application to southern hake. ICES J. Mar. Sci. 69: 1957-1962. https://doi.org/10.1093/icesjms/fsq116

Da Rocha J.M., Gutiérrez M.J., Antelo L.T. 2012a. Pulse vs. optimal stationary fishing: The Northern Stock of hake. Fish. Res. 121-122: 51-62. https://doi.org/10.1016/j.fishres.2012.01.009

Da Rocha J.M., Gutiérrez M.J., Cerviño S. 2012b. Reference points based on dynamic optimization: a versatile algorithm for mixedfishery management with bioeconomic age-structured models. ICES J. Mar. Sci. 69: 660-669. https://doi.org/10.1093/icesjms/fss012

Da Rocha J.M., Gutiérrez, M. J., Antelo L.T. 2013. Selectivity, pulse fishing and endogenous lifespan in Beverton-Holt models. Environ. Resour. Econ. 54: 139-154. https://doi.org/10.1007/s10640-012-9585-Z

Da Rocha J.M., García Cutrín J., Gutiérrez M.J., et al. 2016. Reconciling yield stability with international fisheries agencies precautionary preferences: The role of non constant discount factors in age structured models. Fish. Res. 173: 282-293. https://doi.org/10.1016/j.fishres.2015.08.024

de Vos B., Döring R., Aranda M., et al. 2016. New modes of fisheries governance: Implementation of the landing obligation in four European countries. Mar. Policy 64: 1-8. https://doi.org/10.1016/j.marpol.2015.11.005

Deval M., Özgen G., Özbilgin H. 2006. Selectivity of 50mm T0 and T90 codends for commercial shrimp species in the Turkish deepwater trawl fishery, Eastern Mediterranean. J. Appl. Ichthyol. 32: 1041-1057. https://doi.org/10.1111/jai.13128

Directorate-General for Maritime Affairs and Fisheries (EC). 2017. Support from the European Maritime and Fisheries Fund (EMFF). Opportunities for small-scale coastal fishermen. European Union Publications. https://doi.org/10.2771/230641

Dunn D., Boustany A., Halpin P. 2011. Spatio-temporal management of fisheries to reduce by-catch and increase fishing selectivity. Fish Fish. 12: 110-119. https://doi.org/10.1111/j.1467-2979.2010.00388.x

European Council (EC). 2005. Council Regulation No 2166/2005 of 20 December 2005 establishing measures for the recovery of the Southern hake and Norway lobster stocks in the Cantabrian Sea and Western Iberian peninsula and amending Regulation (EC) No. 850/98 for the conservation of fishery resources through technical measures for the protection of juveniles of marine organisms. Off. J. European Union, L 345.

European Union (EU). 2013. Regulation (EU) no 1380/2013 of the European Parliament and of the Council of 11 December 2013 on the Common Fisheries Policy, amending Council Regulations (EC) no 1954/2003 and (EC) no 1224/2009 and repealing Council Regulations (EC) no 2371/2002 and (EC) no 639/2004 and Council Decision 2004/585/EC. Off. J. European Union.

European Union (EU). 2014. Regulation (EU) No 508/2014 of the European Parliament and of the Council of 15 May 2014 on the European Maritime and Fisheries Fund and repealing Council Regulations (EC) No 2328/2003, (EC) No 861/2006, (EC) No $1198 / 2006$ and (EC) No 791/2007 and Regulation (EU) No 1255/2011 of the European Parliament and of the Council. Off. J. European Union, L 149/1.

Feekings J., Bartolino V., Madsen N., et al. 2012. Fishery discards: 
Factors affecting their variability within a demersal trawl fishery. PLoS ONE 7: e36409.

https://doi.org/10.1371/journal.pone.0036409

Fernández C., Cerviño S., Pérez N., et al. 2010. Stock assessment and projections incorporating discards estimates in some years: An application to the hake stock in ICES divisions VIIIc and IXa. ICES J. Mar. Sci. 67: 1185-1197. https://doi.org/10.1093/icesjms/fsq029

García D., Urtizberea A., Diez G., et al. 2013. Bioeconomic management strategy evaluation of deep water stocks using the FLBEIA model. Aquat Living Resour. 26: 365-379. https://doi.org/10.1051/alr/2013069

García D., Prellezo R., Sampedro P., et al. 2016. Bioeconomic multistock reference points as a tool for overcoming the drawbacks of the landing obligation. ICES J. Mar. Sci. 74: 511-524. https://doi.org/10.1093/icesjms/fsw030

Gorelli G., Company J., Bahamón N., et al. 2017. Improving codend selectivity in the fishery of the deep-sea red shrimp Aristeus antennatus in the northwestern Mediterranean Sea. Sci. Mar. 81: 381-386. https://doi.org/10.3989/scimar.04575.25A

Guillen J., Macher C., Merzéréaud M., et al. 2014. The effect of discards and survival rate on the Maximum Sustainable Yield estimation based on landings or catches maximisation: Application to the nephrops fishery in the Bay of Biscay. Mar. Policy 50: 207-214. https://doi.org/10.1016/j.marpol.2014.06.005

Heikinheimo O., Setälä J., Saarni K., et al. 2006. Impacts of meshsize regulation of gillnets on the pikeperch fisheries in the Archipelago Sea, Finland. Fish. Res. 77: 192-199. https://doi.org/10.1016/j.fishres.2005.11.005

Herrmann B., Priour D., Ludvig A. 2007. Simulation-based study of the combined effect on codend size selection of turning meshes by 90 and reducing the number of meshes in the circumference for round fish. Fish. Res. 84: 222-232. https://doi.org/10.1016/j.fishres.2006.10.020

ICES. 2015. Working Group on the Assessment of Southern Shelf Stocks of Hake, Monk and Megrim. Multiannual Management Plans SWW Meeting (WGHMM). Vigo, May 25-29th.

ICES. 2016. Report of the Working Group for the Bay of Biscay and the Iberian waters Ecoregion (WGBIE). 13-19 May 2016, ICES Headquarters, Copenhagen, Denmark. ICES CM/ACOM:12. $513 \mathrm{pp}$.

ICES. 2017a. Mixed fisheries advice for the Bay of Biscay and Atlantic Iberian Waters. ICES Advice on fishing opportunities, catch, and effort Bay of Biscay and Iberian Coast Ecoregion. Published 30 June 2017. https://doi.org/10.17895/ices.pub.3157

ICES. 2017b. Report of the Working Group for the Bay of Biscay and Iberian waters Ecoregion (WGBIE). 4-11 May 2017, ICES Headquarters, Copenhagen, Denmark. ICES CM/ACOM:12. 534 pp.

ICES. 2017c. Report of the Working Group on Mixed Fisheries Advice (WGMIXFISH- ADVICE). 22-27 May 2017, ICES Headquarters, Copenhagen, Denmark. ICES CM/ACOM:12. 128 pp.

Kayka H., Toka A., Özbilgin H. 2009. Selectivity of commercial, larger mesh and square mesh trawl codends for deep water rose shrimp Parapenaeus longirostris (Lucas, 1846) in the Aegean Sea. Sci. Mar. 73: 597-604. https://doi.org/10.3989/scimar.2009.73n3597

Kelleher K. 2005. Discards in the world's marine fisheries. Un update. FAO Fish. Tech. Pap. 470: 1-131.

Kennelly S., Broadhurst M. 2002. Bycatch begone: changes in the philosophy of fishing technology. Fish Fish. 3: 340-355. https://doi.org/10.1046/j.1467-2979.2002.00090.x

Kraak S., Bailey N., Cardinale M., et al. 2013. Lessons for fisheries management from the EU cod recovery plan. Mar. Policy 37: 200-213. https://doi.org/10.1016/j.marpol.2012.05.002

Leontief W. 1944. The Structure of the American Economy 19191929. Harvard Univ. Press, Cambridge, MA

Macher C., Guyader O., Talidec C., et al. 2008. A cost-benefit analysis of improving trawl selectivity in the case of discards: The Nephrops norvegicus fishery in the Bay of Biscay. Fish. Res. 92: 76-89. https://doi.org/10.1016/j.fishres.2007.12.021

Madsen N., Holst R., Foldager L. 2002. Escape windows to improve the size selectivity in the Baltic cod trawl fishery. Fish. Res. 57: 223-235.
https://doi.org/10.1016/S0165-7836(01)00355-1

Maeda E.E., Mäntyniemi S., Despoti S., et al. 2017. A bayesian model of fisheries discards with flexible structure and priors defined by experts. Ecol. Model. 366: 1-14. https://doi.org/10.1016/j.ecolmodel.2017.10.007

Mortensen L., Ulrich C., Eliasen S., et al. 2017. Reducing discards without reducing profit: free gear choice in a Danish resultbased management trial. ICES J. Mar. Sci. 74: 1469-1479. https://doi.org/10.1093/icesjms/fsw209

Mytilineou C., Politou C., Fourtouni A. 1998. Trawl selectivity studies on Nephrops norvegicus (L.) in the eastern Mediterranean Sea. Sci. Mar. 62(Suppl. 1): 107-116.

Prellezo R., Carmona I., García D. 2016. The bad, the good and the very good of the landing obligation implementation in the Bay of Biscay: A case study of Basque trawlers. Fish. Res. 181: $172-185$. https://doi.org/10.1016/j.fishres.2016.04.016

Prellezo R., Carmona I., García D., et al. 2017. Bioeconomic assessment of a change in fishing gear selectivity: the case of a single-species fleet affected by the landing obligation. Sci. Mar. 81: 371-380. https://doi.org/10.3989/scimar.04597.18A

Revill A. 2012. Survival of discarded fish, a rapid review of studies on discard survival rates. Work produced in response to: Request for services commitment No s12.615631, European Commission, Directorate-general for Maritime Affairs and Fisheries. Policy development and coordination. Brussels, MAREA2.

Sánchez P., Demestre M., Martín P. 2004. Characterisation of the discards generated by bottom trawling in the northwestern Mediterranean. Fish. Res. 67: 71-80. https://doi.org/10.1016/j.fishres.2003.08.004

Sánchez P., Sartor P., Recasens L., et al. 2007. Trawl catch composition during different fishing intensity periods in two Mediterranean demersal fishing grounds. Sci. Mar. 71: 765-773. https://doi.org/10.3989/scimar.2007.71n4765

Schrope M. 2010. What's the catch? Nature 465: 540-542. https://doi.org/10.1038/465540a

Shepherd J.G. 1982. Food for thought: pretty good multispecies yield. J. Cons. Int. Explor. Mer. 40: 67-75. https://doi.org/10.1093/icesjms/40.1.67

Suuronen P., Sardá F. 2007. By-catch reduction techniques in European fisheries: Traditional methods and potential innovations. In: Kennelly S. (ed.), By-catch Reduction in the World's Fisheries. Springer, Dordrecht, The Netherlands. pp. 37-74 https://doi.org/10.1007/978-1-4020-6078-6_3

Tokaç A., Herrmann B., Aydına C., et al. 2014. Predictive models and comparison of the selectivity of standard (T0) and turned mesh (T90) codends for three species in the Eastern Mediterranean. Fish. Res. 150: 76-88. https://doi.org/10.1016/j.fishres.2013.10.015

Tolotti M., Filmalter J., Bacha P., et al. 2015. Banning is not enough: The complexities of oceanic shark management by tuna regional fisheries management organizations. Glob. Ecol. Conserv. 4: 1-7. https://doi.org/10.1016/j.gecco.2015.05.003

Tsagarakis K., Palialexis A., Vassilopoulou V. 2014. Mediterranean fishery discards: review of the existing knowledge. ICES J. Mar. Sci. 71: 1219-1234 https://doi.org/10.1093/icesjms/fst074

Uhlmann S, van Helmond A Stefánsdóttir E., et al. 2014. Discarded fish in European waters: general patterns and contrasts. ICES J. Mar. Sci. 71: 1235-1245 https://doi.org/10.1093/icesjms/fst030

Villasante S., Pierce G., Pita C., et al. 2016a. Fishers' perceptions about the EU discards policy and its economic impact on smallscale fisheries in Galicia (North West Spain). Ecol. Econ. 130: $130-138$. https://doi.org/10.1016/j.ecolecon.2016.05.008

Villasante S., Pita C., Pierce G., et al. 2016b. To land or not to land: How do stakeholders perceive the zero discard policy in European small-scale fisheries? Mar. Policy 71: 166-174. https://doi.org/10.1016/j.marpol.2016.05.004

Vázquez-Rowe I., Moreira M., Feijoo G. 2011. Estimating global discards and their potential reduction for the Galician fishing fleet (NW Spain). Mar. Policy 35: 140-147. https://doi.org/10.1016/j.marpol.2010.08.012 


\section{APPENDIXES}

Appendix 1. - SIHS. Parameters of the age-structure model for hake. Source: ICES Working Group on the Assessment of Southern Shelf Stocks of Hake, Monk, and Megrim (ICES 2015).

\begin{tabular}{|c|c|c|c|c|c|c|}
\hline Age & $\begin{array}{l}\text { Abundance } \\
\text { (thousands) }\end{array}$ & Natural & $\begin{array}{l}\text { Mortality } \\
\text { Landings }\end{array}$ & Discards & Maturity & $\begin{array}{l}\text { Weight } \\
\text { (kg) }\end{array}$ \\
\hline 0 & 92516 & 0.4 & 0.00 & 0.06 & 0.00 & 0.01 \\
\hline 1 & 61742 & 0.4 & 0.26 & 0.23 & 0.08 & 0.12 \\
\hline 2 & 37602 & 0.4 & 0.83 & 0.10 & 0.70 & 0.46 \\
\hline 3 & 10508 & 0.4 & 0.92 & 0.04 & 0.98 & 1.10 \\
\hline 4 & 3150 & 0.4 & 0.92 & 0.01 & 0.99 & 2.01 \\
\hline 5 & 486 & 0.4 & 0.92 & 0.01 & 1.00 & 3.09 \\
\hline 6 & 137 & 0.4 & 0.92 & 0.00 & 1.00 & 4.26 \\
\hline 7 & 28 & 0.4 & 0.92 & 0.00 & 1.00 & 5.46 \\
\hline 8 & 6 & 0.4 & 0.92 & 0.00 & 1.00 & 6.62 \\
\hline 9 & 2 & 0.4 & 0.92 & 0.00 & 1.00 & 7.71 \\
\hline 10 & 1 & 0.4 & 0.92 & 0.00 & 1.00 & 10.00 \\
\hline
\end{tabular}

Appendix 2. - SIHS. Parameters of the age-structure model for secondary species. Source: ICES Working Group on the Assessment of Southern Shelf Stocks of Hake, Monk, and Megrim (ICES 2015).

\begin{tabular}{|c|c|c|c|c|c|}
\hline \multirow[t]{2}{*}{ Age } & \multirow{2}{*}{$\begin{array}{c}\text { Abundance } \\
\text { (2011, thousands) }\end{array}$} & \multicolumn{2}{|c|}{ Mortality } & \multirow[t]{2}{*}{ Maturity } & \multirow{2}{*}{$\begin{array}{l}\text { Weight } \\
(\mathrm{kg})\end{array}$} \\
\hline & & Natural & Fishing & & \\
\hline \multicolumn{6}{|c|}{ Megrim Lepidorhombus whiffiagonis (MGW) } \\
\hline 0 & 2504 & 0.2 & 0.012 & 0.34 & 0.062 \\
\hline 1 & 4357 & 0.2 & 0.096 & 0.90 & 0.092 \\
\hline 2 & 780 & 0.2 & 0.134 & 1.00 & 0.123 \\
\hline 3 & 704 & 0.2 & 0.177 & 1.00 & 0.158 \\
\hline 4 & 751 & 0.2 & 0.283 & 1.00 & 0.193 \\
\hline 5 & 362 & 0.2 & 0.294 & 1.00 & 0.241 \\
\hline 6 & 275 & 0.2 & 0.294 & 1.00 & 0.396 \\
\hline \multicolumn{6}{|c|}{ Megrim Lepidorhombus boscii (MGB) } \\
\hline 0 & 2504 & 0.2 & 0.012 & 0.34 & 0.062 \\
\hline 0 & 24016 & 0.2 & 0.000 & 0.00 & 0.003 \\
\hline 1 & 17855 & 0.2 & 0.001 & 0.55 & 0.037 \\
\hline 2 & 23296 & 0.2 & 0.079 & 0.86 & 0.070 \\
\hline 3 & 10209 & 0.2 & 0.275 & 0.97 & 0.088 \\
\hline 4 & 6879 & 0.2 & 0.513 & 0.99 & 0.110 \\
\hline 5 & 3734 & 0.2 & 0.535 & 1.00 & 0.145 \\
\hline 6 & 2766 & 0.2 & 0.401 & 1.00 & 0.186 \\
\hline 7 & 1417 & 0.2 & 0.401 & 1.00 & 0.265 \\
\hline \multicolumn{6}{|c|}{ Monkfisk Lophius piscatorius (MON) } \\
\hline 0 & 2504 & 0.2 & 0.012 & 0.34 & 0.062 \\
\hline 0 & 855 & 0.2 & 0.013 & 0.01 & 0.001 \\
\hline 1 & 920 & 0.2 & 0.120 & 0.09 & 0.681 \\
\hline 2 & 366 & 0.2 & 0.202 & 0.28 & 1.922 \\
\hline 3 & 162 & 0.2 & 0.288 & 0.53 & 3.843 \\
\hline 4 & 161 & 0.2 & 0.334 & 0.73 & 6.398 \\
\hline 5 & 212 & 0.2 & 0.319 & 0.85 & 9.483 \\
\hline 6 & 105 & 0.2 & 0.272 & 0.91 & 12.956 \\
\hline 7 & 76 & 0.2 & 0.219 & 0.94 & 16.748 \\
\hline 8 & 12 & 0.2 & 0.173 & 0.96 & 20.834 \\
\hline 9 & 29 & 0.2 & 0.136 & 0.98 & 25.132 \\
\hline 10 & 37 & 0.2 & 0.108 & $\begin{array}{l}0.70 \\
0.98\end{array}$ & 29.497 \\
\hline 11 & 5 & 0.2 & 0.088 & 0.99 & 33.788 \\
\hline 12 & 4 & 0.2 & 0.072 & 0.99 & 37.914 \\
\hline 13 & 15 & 0.2 & 0.030 & 1.00 & 52.467 \\
\hline
\end{tabular}

